\title{
Impacts of COVID-19 Pandemic on Employees' Anxiety and Safety Behavior at Higher Educational Institutions in Banjarmasin
}

\author{
Rizky Nastiti \\ Sekolah Tinggi Ilmu Ekonomi Indonesia Banjarmasin \\ Devi Rusvitawati \\ Sekolah Tinggi Ilmu Manajemen Indonesia Banjarmasin \\ *rizky@stiei-kayutangi-bjm.ac.id
}

\begin{abstract}
The policy to return to work amidst the pandemic has caused anxiety among employees, including those who work at universities and colleges. In order to maintain organization's performance in the era of COVID-19, the management needs to pay attention to employees' adjustment and well-being. Moreover, figuring out employees' anxiety level and safety behavior during the pandemic will help the managements ease their employees' anxiety and improve their work performance. Thus, this study focuses on the impacts of COVID-19 on employees' anxiety and safety behavior at higher educational institutions in Banjarmasin. A total of 78 responses were collected from employees of higher educational institutions in Banjarmasin. From the data analysis, it was found that physical concerns and psychological concerns had significant impacts on anxiety and safety behavior. This study offers suggestions for institutions to provide adequate protective equipment safety and enforce their human resource management to help their employees cope with new work environment.
\end{abstract}

Keywords: COVID-19, pandemic, anxiety, safety behavior

\section{Introduction}

The worldwide outbreak of the COVID-19 pandemic has had a huge impact on people's lives, health, and livelihood. Many countries have put various levels of social restrictions in place in order to minimize the spread. In the beginning of the outbreak, especially in Indonesia, many educational institutions, offices, stores, shopping malls and public places were closed. People were advised to stay home except for essential trips for food, to the pharmacist, or the hospital. However, after so many months, businesses and offices could not afford to stay closed. Therefore, they decided to open their businesses and offices by either implementing shift work system or setting limit on working hours.

Currently in Banjarmasin, many businesses and offices, including universities and colleges, continue to operate by implementing health protocols proposed by Circular Letter of Ministry of Health of the Republic of Indonesia (2020). Even though the offices have followed the recommended protocols, working in an office where large crowds of people gather raises anxiety among employees about the transmission of COVID-19. Thus, the protection of the mental health of employees should be integrated into workplace occupational safety and health management systems (OSH-MS) in order to maintain to employees' adjustment and well-being (ILO, 2020).

Employees working at universities and colleges come into direct and indirect contact with various visitors, for example: students, and work in closed spaces. They may experience psychological burdens and extreme stress due to the nature of the contact that occurs in the 


\section{Rizky Nastiti, Devi Rusvitawati}

process of interacting with the colleagues and visitors. A study conducted by Van Der FeltzCornelis et al. (2020) concluded that University of York staff and students reported high psychological distress, presenteeism and absenteeism. It was found that, the staff exhibited psychological symptoms such as worries and physical symptom due to stress.

Anxiety is one of most prevalent mental health problems found during the COVID-19 pandemic (Achenbach, 2020; Kluger, 2020). Dozois (2020) conducted a national survey focused on anxiety and depression in Canada during COVID-19 pandemic. Dozois pointed out that during the pandemic Canadians are experiencing considerable anxiety and depression. The study also predicted that depression would worsen should physical distancing and self-isolation continue for much longer. Moreover, Trougakos et al. (2020) concluded that feelings of fear and apprehension about having or contracting COVID-19 impacted critical work, home, and health outcomes. This COVID-19 health anxiety resulted in engaging in appropriate coping behaviors, such as hand washing since it has been widely recommended as a way to fight the spread of COVID-19.

Furthermore, the implementation of health protocol during the pandemic is also one of coping behaviors in suppressing the anxiety about being infected with COVID-19. The recommendations to wear mask, maintain physical distance and maintain personal hygiene must be adhered to, especially when in public places. Return to work must be evaluated and, later, implemented as a national public policy that coordinates and manages activities in companies and organizations, according to the International Labor Organization (ILO, 2020). In order to minimize the risk of outbreak, the businesses and offices that issue returning to work have to implement measures according to the hierarchy of controls (Filho and Algranti, 2020).

Moreover, figuring out employees' anxiety level and safety behavior during the pandemic will help the managements ease their employees' anxiety and improve their work performance. Therefore, this study focuses on the attributed perceived pandemic concerns that cover physical concerns and psychological concerns. Furthermore, this study also investigates the impact of physical concerns and psychological concerns on employees' anxiety and safety behavior.

\section{Literature Review}

\section{Working during Pandemic}

The policy to return to work amidst the pandemic has caused anxiety among employees. Wong et al. (2020) in their study pointed that lack of workplace policy in place, insufficient comprehensiveness, lack of timeliness, and lack of protective equipment supply are the causes of the increase in employees' stress level. Their study highlighted workplace policy should be further strengthened in both government and organization setting.

Ministry of Health of the Republic of Indonesia (2020) has provided guidelines for employees' protection in workplace. To ensure workplace safety during COVID-19 outbreak, some protocols are recommended, including: (1) facility cleaning; (2) hand-washing; (3) optimizing air circulation and sunlight; (4) providing masks, tissues and separated workplace for sick employees; (5) informing and promoting Clean and Healthy Living Behavior and self-isolation protocol; and (6) implementing other risk control of COVID-19 transmission, such as installing barriers to provide contact distance (engineering control), setting working hours, working shifts, teleworking, flexible working hours (administrative control), and others. 


\section{Rizky Nastiti, Devi Rusvitawati}

However, according to Sasaki et al. (2020), the fear of COVID-19 was positively associated with the number of workplace measures taken to respond to COVID-19. The employees' anxiety and worry regarding COVID-19 could be caused by increased contamination awareness in relation to the kind of workplace measures implemented (Sasaki et al., 2020; Parlapani et al., 2020).

\section{Anxiety}

Crisis conditions, such as the recent coronavirus pandemic, have been shown in studies to have a detrimental effect on mental health. The possibility of becoming infected with COVID-19 can cause extreme concern. This anxiety can affect people's psychological well-being (Kang et al., 2020; Mukhtar, 2020; Pakpour and Griffiths, 2020; Taylor et al., 2020; Wang et al., 2020).

Nikčević and Spada (2020) conducted a study to develop COVID-19 anxiety syndrome scale. In addition, Silva et al. (2020) also developed COVID-19 Anxiety Scale (CAS). Their studies pointed out that women presented higher levels of anxiety than men. Both studies show that it is extremely necessary to measure anxiety caused by the pandemic. One of the reasons is there has been an alarming rise in cases of anxiety symptoms that call into question people's wellbeing and sense of security about their lives. Moreover, the findings of anxiety studies conducted during the pandemic can be seen as a benchmark for predicting similar incidents in the future.

Furthermore, mental health services around the world are unprepared to cope with the pandemic's short-term and long-term impacts. Thus, in order to establish and disseminate effective treatments for the general population and other at-risk groups, a clear picture of the effects that this new stressor can have on mental health and well-being is needed (Giallonardo et al., 2020).

\section{Safety Behavior}

During the pandemic, the fear of viral transmission is related to precautionary measures and avoidant behavior to prevent infection. WHO (2020), since the beginning of the pandemic, has promoted preventive behaviors such as frequent hand hygiene, avoiding touching the face, wearing a medical mask and maintaining physical distance.

Trougakos et al. (2020) highlighted the importance of engaging in appropriate coping behaviors relevant to the situation individuals are dealing with the pandemic, such as hand washing. It is because hand washing has been widely recommended as a way to prevent the infection of COVID-19. However, according to Parlapani et al. (2020), the excessive implementation of safety behaviors and stricter adherence to health protocols, as the ways to prevents infection, were shown to increase anxiety. This situation was possibly due to increased contamination awareness.

\section{Relationship among Study Variables}

Yu et al. (2021) in their study identified four attributes of epidemic concern perceived by hotel employees. The concerns are physical concerns, psychological concerns, financial concerns, and concerns regarding social gaze. However, considering the actual situation of the universities and colleges being studied, this study will focus only on physical and psychological concerns. 
In this study, physical concerns refer to the physical fatigue and discomfort felt by the employees while working during the pandemic. While psychological concerns refer to the anxiety and worry felt by the employees while working during the pandemic. By using the instrument adapted from $\mathrm{Yu}$ et al. (2021), three items related to physical concerns are asked to the respondents including: (1) physical fatigue due to additional work such as frequent cleaning and disinfecting; (2) discomfort due to wearing a mask or safety equipment when interacting with others; and (3) physical fatigue due to paying more attention to personal hygiene, such as hand washing. Moreover, four items related to psychological concerns are asked to the respondents including: (1) anxiety over the possibility of getting infected by colleagues and visitors; (2) anxiety over the possibility of interacting with infected colleagues and visitors; (3) anxiety over the possibility of passing COVID-19 to family members; and (4) anxiety over the possibility of getting infected and causing the closure of workplace.

In addition, in order to minimize their anxiety, the employees followed personal safety behaviors, such as cleaning/disinfecting objects, taking care of personal hygiene and wearing masks. These behaviors are expected to minimize the risks of being infected by COVID-19.

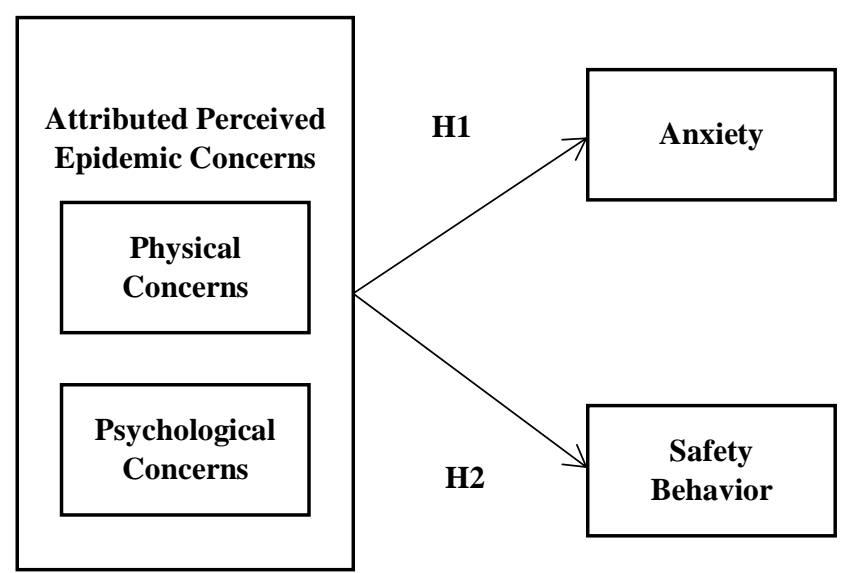

Figure 1. Research Framework

$\mathrm{H}_{1}$ : Physical concerns and psychological concerns of attributed perceived pandemic concerns have positive impact on anxiety.

$\mathrm{H}_{2}$ : Physical concerns and psychological concerns of attributed perceived pandemic concerns have positive impact on safety behavior.

\section{Research Method}

This study was quantitative study focused on investigating the relationship between of attributed perceived pandemic concerns, anxiety and safety behavior. There were three variables in this study, including (1) attributed perceived pandemic concerns that covered physical concerns and psychological concerns; (2) anxiety; and (3) safety behavior. Questionnaire was used as the instrument of this study.

The items of attributed perceived pandemic concerns were adapted from $\mathrm{Yu}$ et al. (2021) and rated by the respondent by using 5-point Likert scale. While, the items of anxiety were adapted from the COVID-19 anxiety syndrome scale developed by Nikčević and Spada (2020). There were ten items asked in order to measure the anxiety level. The respondents were asked to rate the extent to which each item or statement applied to the respondents over 


\section{Rizky Nastiti, Devi Rusvitawati}

the last two weeks by using a five-point scale to indicate their level of agreement ("Nearly every day", "More than seven days", "Several days", "Rarely" and "Not at all"). In addition, in order to measure safety behavior, six items adapted from Parlapani et al. (2020) and Dewi and Probandari (2021) were rated by respondents by using a five-point scale ("Always", "Often", "Sometimes", "Rarely", "Never").

A total of 78 responses were collected randomly from employees of five universities and colleges in Banjarmasin. In order to identify the relationship of the variables, hypothesis testing using SPSS was employed.

\section{Validity and Reliability Test}

The validity test of the questionnaire was done by analyzing the responses of 30 respondents by using SPPS. The result showed that the value of Pearson Correlation of all items were greater than the value of $r$ table product moment .361 . Hence, it was concluded that all items in the questionnaire were valid.

After completing the validity test, the test to measure the reliability of the instrument was conducted. The result of the reliability test showed that all items were reliable since the value of Cronbach's Alpha was greater than .600 as can be seen in Table 1 .

Table 1. Reliability Testing Result

\begin{tabular}{|l|c|c|}
\hline \multicolumn{1}{|c|}{ Variable } & Cronbach's Alpha & Detail \\
\hline Attributed Perceived Pandemic Concerns & .788 & Reliable \\
Anxiety & .947 & Reliable \\
Safety Behavior & .785 & Reliable \\
\hline
\end{tabular}

Source: primary data, 2021

\section{Findings}

After the questionnaire has been concluded valid and reliable, the questionnaire then distributed to five universities and colleges in Banjarmasin. A total of 78 responses then were collected and analyzed from employees of those higher educational institutions. The characteristics of respondents can be seen in Table 2 .

Table 2. Characteristics of Respondents

\begin{tabular}{|l|c|c|}
\hline \multicolumn{1}{|c|}{ Characteristics } & f & $\%$ \\
\hline Age: & & \\
$\leq 20$ years old & 2 & 2.56 \\
20-30 years old & 37 & 47.44 \\
$31-40$ years old & 20 & 25.64 \\
$41-50$ years old & 13 & 16.67 \\
$>$ 50 years old & 6 & 7.69 \\
Gender: & & \\
Male & 38 & 48.72 \\
Female & 40 & 51.28 \\
Working Period: & & \\
$1-5$ years & 36 & 46.15 \\
$6-10$ years & 22 & 28.21 \\
$11-15$ years & 6 & 7.69 \\
$16-20$ years & 5 & 6.41 \\
\hline
\end{tabular}


INOBIS: Jurnal Inovasi Bisnis dan Manajemen Indonesia

Volume 04, Nomor 02, Maret 2021

Rizky Nastiti, Devi Rusvitawati

\begin{tabular}{|l|c|c|}
\hline$>20$ years & 9 & 11.53 \\
\hline Total & 78 & 100.0 \\
\hline
\end{tabular}

Source: primary data, 2021

Table 3. Descriptive Statistics of Variables

\begin{tabular}{|l|c|c|c|c|}
\hline \multicolumn{1}{|c|}{ Variable } & Minimum & Maximum & Mean & $\begin{array}{c}\text { Std. } \\
\text { Deviation }\end{array}$ \\
\hline Attributed Perceived & 1 & 5 & 3.60 & .81764 \\
Pandemic Concerns & & & & \\
Anxiety & 1 & 5 & 3.24 & .97959 \\
Safety Behavior & 1 & 5 & 4.19 & .68412 \\
\hline
\end{tabular}

Source: primary data, 2021

Table 3 showed the descriptive statistics of each variable. The mean of physical concerns and psychological concerns variable was 3.60. This result meant that in general the respondents had quite high concern about COVID-19, especially of being infected by colleagues or visitors in workplace and exposing the family members to the epidemic. Meanwhile, the mean of anxiety variable was 3.24. This result meant that the level of anxiety of the respondents in average was moderate. In general, the respondents tried to avoid being infected by avoiding going out to public places, touching things in public spaces and engaging in social activities that involved many people. Furthermore, from the mean of safety behavior variables 4.19 , it could be concluded that the respondents often adhered to health protocol, especially wearing mask in workplace, changing mask frequently and washing hands regularly.

\section{Hypothesis Testing}

Table 4. Hypothesis Testing Result

\begin{tabular}{|c|c|c|c|}
\hline Hypothesis & t-Test & Sig. & Decision \\
\hline $\begin{array}{l}\text { Physical concerns and } \\
\text { psychological concerns of } \\
\text { attributed perceived pandemic } \\
\text { concerns have positive impact on } \\
\text { anxiety. }\end{array}$ & 10.649 & .000 & Accepted \\
\hline $\begin{array}{l}\text { Physical concerns and } \\
\text { psychological concerns of } \\
\text { attributed perceived pandemic } \\
\text { concerns have positive impact on } \\
\text { safety behavior. }\end{array}$ & 7.379 & .000 & Accepted \\
\hline
\end{tabular}

Source: primary data, 2021

The first hypothesis proposed that physical concerns and psychological concerns of attributed perceived pandemic concerns have positive impact on anxiety. The result displayed on Table 4 showed that the significance value of $.000<0.05$. Thus, the first hypothesis was accepted.

The second hypothesis proposed that physical concerns and psychological concerns of attributed perceived pandemic concerns have positive impact on safety behavior. The result 
displayed on Table 4 showed that the significance value of $.000<0.05$. Thus, the second hypothesis was accepted.

\section{Discussions}

Evidences suggest that the current pandemic has consequences for people's mental health. The need to assess the fluctuations in anxiety caused by the pandemic needs to be adressed due to an alarming rate of increase in cases of anxiety symptoms, fears about the future, and uncertainty of security about lives. Moreover, assessing anxiety during a pandemic may be useful as a parameter for predicting similar events in the future. The result of analysis reveals that physical concerns and psychological concerns affect employees' anxiety.This result is consistent with the result of the studies conducted by Achenbach (2020) and Kluger (2020) that concluded that anxiety is one of most prevalent mental health problems found during the COVID-19 pandemic. This study also highlights the employees' main concerns about working during the pandemic. In general, the employees mostly worry about being infected by their collagues or visitors in their workplace. They also worry that their family members might also be exposed to COVID-19 because they prone to exposed to it in their workplace.

The assessment result of employees' anxiety level shows that by returning to work, the employees' worry about the possibility of being infected is increasing. However, their anxiety level is considered as moderate. In addition, many employees admit that they have avoided touching things in public spaces because of the fear of contracting the virus. They also have avoided going out to public places such as shops, parks, and markets because of the fear of contracting COVID-19. Moreover, many employees also have researched symptoms of COVID-19 so that they avoid social activities involving many people.

Furthermore, the anxiety of COVID-19 transmission is linked to infection-prevention precautions and avoidant behaviors. The result of this study points out that physical concerns and psychological concerns affect employees' safety behavior. In addition, from the findings, it can be concluded that in general the employees obey the health protocol promoted by government and workplace. They especially follow the policies to wear mask in workplace, change mask frequently and wash hands regularly. This result is in line with the result of study conducted by Pariapani et al. (2020). Their study proposes that the fear of being infected during a pandemic is related with precautionary measures, such as wearing mask, taking care of personal hygiene, and cleaning the objects after using them.

In addition, it is also found that some employees even admit that they overdo the preventive measure by always disinfecting their belongings before and after using them. Moreover, some employees admit that it is hard to maintain physical distance at workplace since they have to interact with their collagues to carry out their works.

In summary, in order to reduce the employees' anxiety, the institutions need to ensure the well-being of the employees who are working during the pandemic. Moreover, according to Sasaki et al. (2020), the measures taken by the workplace to minimize the infection risk during the pandemic may support and maintain employees' mental health and work performance. Furthermore, it is necessary to establish further guidance on how organizations can adapt their human resource practices in ways that alleviate the above problems and enhance the ability of employees to thrive during dynamic and uncertain times. 


\section{Conclusions}

In order to maintain organization's performance in the era of COVID-19, the management needs to pay attention to employees' adjustment and well-being. From the data analysis, it is concluded that physical concerns and psychological concerns have significant impacts on anxiety and safety behavior. The main concerns of the employees are being infected by colleagues or visitors in workplace and exposing the family members to the epidemic. In addition, even though the employee's anxiety level is moderate, they still adhere to health protocol.

This study offers suggestion for the institutions to provide adequate protective equipment safety. It is also the responsibility of human resource management to help their employees cope with new work environment. Moreover, according to Carnevale and Hatak (2020), human resource management have to help the employees adjust to "new" work condition, such as new workplace policies and procedures to limit human contact. In addition, Dubey et al. (2020) concluded that the management needs to increase awareness, share information and new policies in order to minimize the risk of COVID-19 infection. Furthermore, the institutions need to pay more attention to employees' mental health during this pandemic, especially anxiety and stress levels. As stated by Wong et al. (2020), assuring employees' mental health is important during the pandemic to prevent post-traumatic stress.

Since this study only focuses on the effect of physical concerns and psychological on the employees' anxiety and safety behavior, it offers many possibilities to explore. There are still many variables, related to employees' well-being, that are being effected by the pandemic, such as work stress, motivation and resilience.

\section{References}

Achenbach, J. (2020). Coronavirus is Harming the Mental Health of Tens of Millions of People in U.S., New Poll finds. Washington Post. Retrieved from https://www.washingtonpost.com/health/coronavirus-isharming- the-mental-healthof-tens-of-millions-of-people-in-us-newpoll- finds/2020/04/02/565e6744-74ee-11 ea85cb-8670579b863d_story.html

Carnevale, J. B., and Hatak, I. (2020). Employee Adjustment and Well-Being in the Era of COVID-19: Implications for Human Resource management. Journal of Business Research 116.

Dewi, Y. K., and Probandari, A. (2021). Covid-19 Risk Factors and Health Protocol Compliance among Mall Employees and Officers in Yogyakarta. Berita Kedokteran Masyarakat, Volume 37 (1).

Dozois, D. J. A., and Mental Health Research Canada (2020). Anxiety and Depression in Canada during the COVID-19 Pandemic: A National Survey. Canadian Psychology/Psychologie Canadienne. Advance online publication.

Dubey, P., Singh, G., Nagaraju, G., Gharat, K., Bharambe, S. D., and Vajarekar, A. S. (2020). Reduction of Workforce due to Impact of Covid-19 and Occupational Health and Safety Management at the Workplace. International Journal of Occupational Safety and Health, Vol.10(2).

International Labour Organization (ILO). (2020). Managing Work-Related Psychosocial Risks during the COVID-19 pandemic. Geneva. 
Giallonardo, V., Sampogna, G., Del Vecchio, V., Luciano, M., Albert, U., Carmassi .C, Carrà, G., Cirulli, F., Dell’Osso, B., Nanni, M.G., Pompili, M., Sani, G., Tortorella, A., Volpe, U., and Fiorillo, A. (2020). The Impact of Quarantine and Physical Distancing Following COVID-19 on Mental Health: Study Protocol of a Multicentric Italian Population Trial. Front. Psychiatry 11:533. doi: 10.3389/fpsyt.2020.00533

Filho, J. M. J., and Algranti, E. (2020). Challenges and Paradoxes of the Return to Work amidst the COVID-19 Pandemic. Revista Brasileira de Saúde Ocupacional.

Kang, L., Li, Y., Hu, S., Chen,M., Yang, C., Yang, B. X.,Wang, Y., Hu, J., Lai, J., Ma, X., Chen, J., Guan, L., Wang, G., Ma, H., and Liu, Z. (2020). The Mental Health of Medical Workers in Wuhan, China Dealing with the 2019 Novel Coronavirus. Lancet Psychiatry, 7(3), e14. https://doi.org/10.1016/S2215-0366(20)30047-X.

Kementerian Kesehatan Republik Indonesia. (2020). Surat Edaran No. HK.02.01/MENKES/216/2020 tentang Protokol Pencegahan Penularan Coronavirus Disease (COVID-19) di Tempat Kerja.

Kluger, J. (2020). The Coronavirus Pandemic May be Causing an Anxiety Pandemic. Time. Retrieved from https://time.com/5808278/ coronavirus-anxiety/

Ministry of Health of the Republic of Indonesia. (2020). Keputusan Menteri Kesehatan Republik Indonesia Nomor HK.01.07/MENKES/328/2020 tentang Panduan Pencegahan dan Pengendalian Corona Virus Disease 2019 (Covid-19) di Tempat Kerja Perkantoran dan Industri dalam Mendukung Keberlangsungan Usaha pada Situasi Pandemi.

Mukhtar, S. (2020). Pakistanis' Mental Health during the COVID-19. Asian Journal of Psychiatry, 51(10), 21-27. https://doi.org/10.1016/j.ajp.2020.102127.

Nikčevića, A. V., and Marcantonio M. Spada, M. M. (2020). The COVID-19 Anxiety Syndrome Scale: Development and Psychometric Properties. Psychiatry Research 292.

Pakpour, A. H., and Griffiths, M. D. (2020). The Fear of COVID-19 and Its Role in Preventive Behaviors. Journal of Concurrent Disorders, 2, 58-63.

Parlapani, E., Holeva, V., Voitsidis, P., Blekas, A., Gliatas, I., Porfyri, G.N., Golemis, A., Papadopoulou, K., Dimitriadou, A., Chatzigeorgiou, A.F., Bairachtari, V., Patsiala, S., Skoupra, M., Papigkioti, K., Kafetzopoulou, C., and Diakogiannis, I. (2020). Psychological and Behavioral Responses to the COVID-19 Pandemic in Greece. Front. Psychiatry 11:821. doi: 10.3389/fpsyt.2020.00821

Sasaki, N., Kuroda, R., Tsuno, K., and Kawakami, N. (2020). Workplace Responses to COVID-19 Associated with Mental Health and Work Performance of Employees in Japan. Journal of Occupational Health.

Silva, W. A. D., Brito, T. R. S., and Pereira, C. R. (2020). COVID-19 Anxiety Scale (CAS): Development and Psychometric Properties. Current Psychology.

Taylor, S., Landry, C., Paluszek, M., Fergus, T. A., McKay, D., and Asmundson, G. J. G. (2020). Development and Initial Validation of the COVID Stress Scales. Journal of Anxiety Disorders.

Van Der Feltz-Cornelis, C.M., Varley, D., Allgar, V. L., and de Beurs, E. (2020). Workplace Stress, Presenteeism, Absenteeism, and Resilience amongst University Staff and Students in the COVID-19 Lockdown. Front. Psychiatry 11.

Wang, C., Pan, R., Wan, X., Tan, Y., Xu, L., Ho, C. S., and Ho, R. C. (2020). Immediate Psychological Responses and Associated Factors during the Initial Stage of the 2019 Coronavirus Disease (COVID-19) Epidemic among the General Population in China. International Journal of Environmental Research and Public Health, 17(5), 1729. 
World Health Organization (WHO). (2020). Rational Use of Personal Protective Equipment (PPE) for Coronavirus Disease (COVID-19). Interim Guidance, March 19, 2020. Retrieved from https:// apps.who.int/iris/bitstream/handle/10665/331498/WHO-2019nCoVIPCPPE_use-2020.2-eng.pdf.

Wong, E., Ho, K. F., Wong, S. Y., Cheung, A. W., and Yeoh, E. (2020). Workplace Safety and Coronavirus Disease (COVID-19) Pandemic: Survey of Employees. Bull World Health Organ. doi: http://dx.doi.org/10.2471/BLT.20.255893

Yu, J., Park, J., and Hyun, S. S. (2021). Impacts of the COVID-19 Pandemic on Employees' Work Stress, Well-Being, Mental Health, Organizational Citizenship Behavior, and Employee-Customer Identification. Journal of Hospitality Marketing \& Management, DOI: $10.1080 / 19368623.2021 .1867283$ 